$\mathbb{T}$ periodica polytechnica

Mechanical Engineering

$54 / 1(2010) 21,26$

doi: 10.3311/pp.me.2010-1.04

web: http://www.pp.bme.hu/me

(c) Periodica Polytechnica 2010

RESEARCH ARTICLE

\section{A new calculation procedure to analyse the energy consumption of air handling units}

\author{
László Kajtár / Miklós Kassai
}

Received 2011-01-10

\begin{abstract}
According to Directive 2002/91/EC on the energy performance of buildings $(E P B D)$ it is important to determine the expected energy consumption of buildings in the designing phase. The existing national and international regulations are inadequate regarding methods to calculate the energy consumption of air handling units. The actual calculation methods are fairly inexact approximations producing a single figure for the monthly energy consumption using average temperature or average enthalpy which only approximately take into account the changing of ambient air. A new calculation procedure was developed to provide a more accurate analysis of the energy consumption of air handling systems and to remedy the above mentioned inadequacies.
\end{abstract}

\section{Keywords}

Air handling units $\cdot$ energy consumption $\cdot$ new calculation procedure

\section{László Kajtár}

Department of Building Service Engineering and Process Engineering, BME, H-1111 Budapest, Bertalan Lajos Street 4-6, Hungary

\section{Miklós Kassai}

Department of Building Service Engineering and Process Engineering, BME, H-1111 Budapest, Bertalan Lajos Street 4-6, Hungary

e-mail: kas.miklos@gmail.com

\section{Introduction}

The population and residential buildings represent almost $40 \%$ of the total energy consumption in Hungary. Their share is similar in the EU countries and if the buildings used in the industrial and transport sector are also taken into consideration, this figure even reaches $50 \%$. The major part of this $50 \%$ is used for air conditioning. From the point of view of sustainable development and international agreements (Kyoto protocol) the reduction of carbon dioxide emissions and energy consumption is an important issue. The energy consumption of air handling units can be calculated in two ways. In the case of working air handling units the actual consumption data can be exactly determined by measurement. But according to Directive 2002/91/EC on the energy performance of buildings (EPBD) it is also important to determine the expected energy consumption of buildings in the designing phase. The directive was implemented by the Decree no. 7/2006 of the Minister Without Portfolio. The decree provides information and methods to calculate the energy consumption of building services but for instance the calculation of the energy consumption of air handling units is still problematic. Effective since 2008, Government Decree 264/2008 (XI. 6.) gives guidelines for the energy audit of boilers and air conditioning systems. The European Committee for Standardization (CEN) prepared the prEN ISO 13790 standard in 2005 which was adopted in Bulgaria, France, Ireland, Poland, Hungary, Slovakia and Slovenia. In Hungary it came into force in 2008 named MSZ EN ISO 13790:2008. Though enabling us to calculate the energy consumption of air handling units the standard uses a rather simplified method which does not take into consideration the method of air moistening during the air handling process and fails to include air handling units which have an energy recovery unit. In addition, changes in weather data are only incorporated by the monthly average temperature, which makes the calculation procedure less exact.

Despite the fact that among European countries Germany leads in the development of building energy standards and calculation methods these methods are still too simplified for the estimation of the energy consumption of air handling units. VDI 2067 can be used to calculate only the energy consumption of air 
handling units for the whole year in spite of the fact that there are air handling units that only operate for some months during the year. Also, this calculation procedure does not take into account the systems which are equipped with an energy recovery unit. Another disadvantage of this standard is that it only calculates the net energy consumption of air handling units and does not indicate primary energy consumption. DIN V 18599 allows for the calculation of primary energy consumption (including pump and fan energy) of ventilation systems but only of air handling types that are incorporated in the standard. This is a restriction as there are air handling units of various structures operating in buildings.

As for the American results in this research field and their standards (ASHRAE) they are even less detailed, only listing the available calculation methods for dimensioning.

During our research our objective was to work out a calculation procedure which is suitable for the analysis of the energy consumption of air handling units taking into account the different and complex air handling processes and the above mentioned inadequacies.

\section{The basis of the theoretical background}

From the perspective of air handling technology the key attributes of outdoor air are temperature, humidity and enthalpy. These values randomly vary from minute to minute. The probability theory starts from a set of elementary results of some experiments (e.g.: air temperature measurement). One single real number can be attributed to each elementary event (the measured temperature). The function obtained through this attribution is called the probability variable. There are discrete and continuous probability distributions. The state of air can take any value within a range and may be regarded as a continuous probability variable. A probability variable may have an expected value, dispersion, distribution and density function.

A probability variable with continuous distribution is characterized by the probability distribution $(F(x))$ and density $(\mathrm{f}(\mathrm{x}))$ functions [1].

The probability that a random variable $\xi$ does not exceed a real value $\mathrm{x}$ is defined as function:

$$
F(x)=P(\xi<x)
$$

and is called distribution function.

The probability that the continuous random variable $\xi$ has a value in an interval $(a, b)$ is written up as:

$$
P(a \leq \xi<b)=F(b)-F(a)=\int_{a}^{b} f(x) d x
$$

A random variable $\xi$ is continuous if its distribution function $F(x)=P(\xi<x)$ can be written as:

$$
F(x)=\int_{-\infty}^{x} f(t) d t
$$

The function $f(t)$ is called the probability density function of the continuous random variable $\xi$.



Fig. 1. Distribution function of ambient air temperature from October until March (Budapest, measured temperatures between 1964-1972) [13]

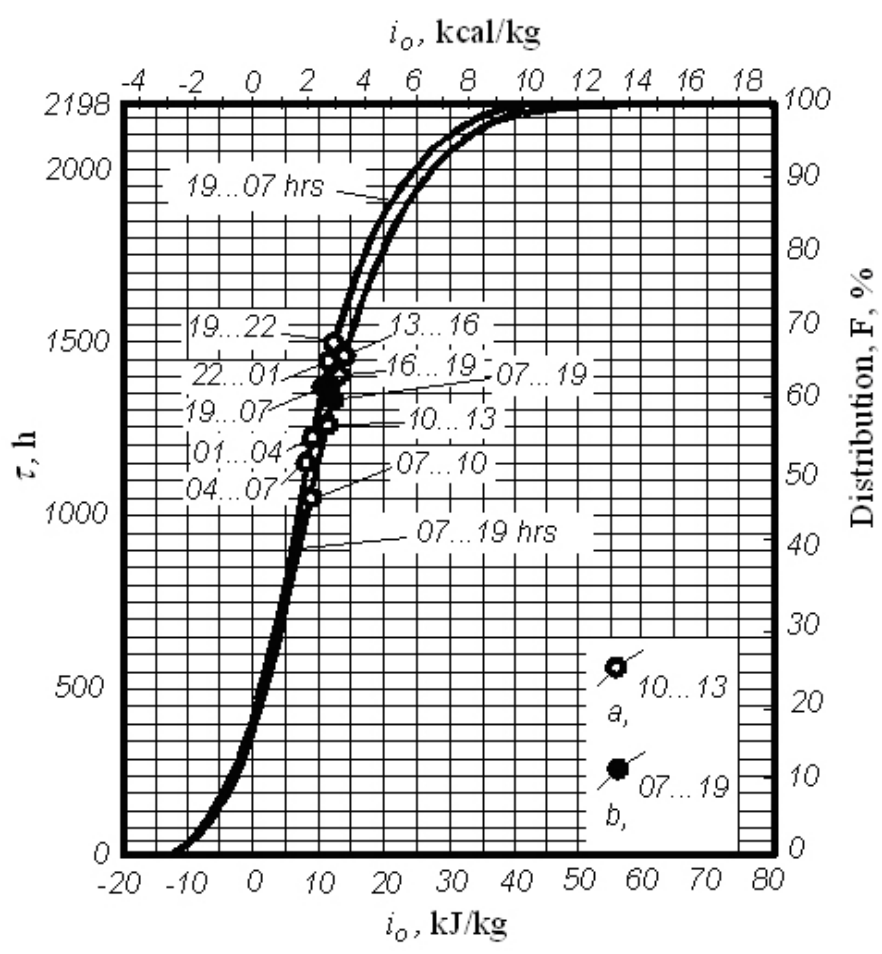

Fig. 2. Distribution function of ambient air enthalpy from October until March (Budapest, measured temperatures between 1964-1972) [13]

The distribution functions of outdoor air parameters (temperature, enthalpy) can be applied to determine the actual energy consumption of air handling units [2-4]. The temperature, humidity and enthalpy of outdoor air can be accounted as continuous distribution probability variables that can be approximated using the Gauss distribution [5-7]. 


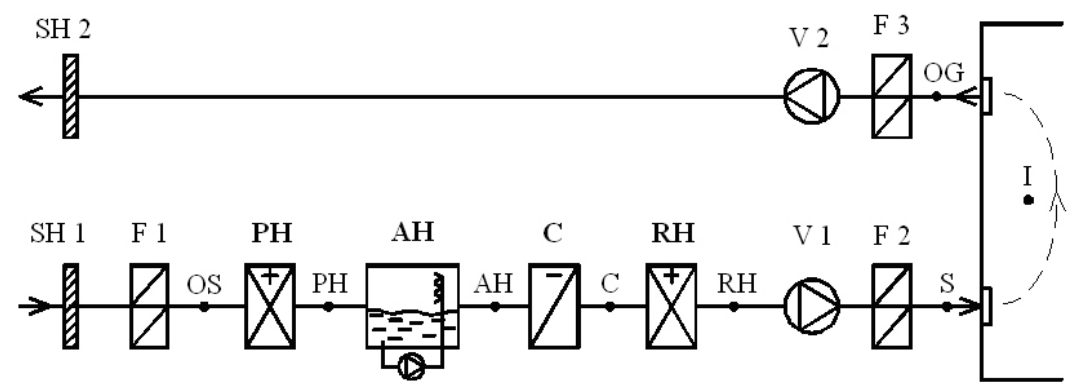

Fig. 3. Connection diagram of AHU

When calculating the energy consumption of heating and cooling it is necessary to take into account the ambient air parameters (temperature, humidity and enthalpy) that vary daily and seasonally $[8-10]$. In the energy calculation of a building the outdoor air condition values can be regarded as a probability variable that has momentary, maximum, minimum and average values as well as a distribution function which can be defined daily, weekly, monthly and annually. We can make more refinements by defining a daytime period (07-19 hours) and a continuous operation (0-24 hours) of air handling units. Temperature and enthalpy distribution functions are shown on Fig. 1 and Fig. 2 which present a daytime (07-19 hours) period and a night period (19-07 hours). Any point of the functions shows the hours and the percentage of the term when the temperature or enthalpy of outdoor air was lower than the examined point. It follows that the $\tau_{\text {tot }}$ term which applies to $100 \%$ distribution is equal to the reference period.

Energy consumption can always be determined by the areas between the functions and the state of the supply air [11,12]. In view of the annual energy consumption operational costs can be calculated if power and heat costs are known.

\section{The physical and mathematical model}

The developed calculation procedure is presented in the article through the example of a fresh air supplied air handling unit (AHU). The connection diagram of this air handling system is shown on Fig. 3. The symbols in the figure are the following:

PH : Pre-heater,

AH : Adiabatic humidifier,

C : Cooler,

$\mathrm{RH}:$ Re-heater,

$\mathrm{V}$ : Ventilator,

$\mathrm{F}$ : Filter,

SH : Shutter against the rain.

During the energy calculations it is important to take into consideration the order of the air handling elements and the air handling processes. During the operation of the air handling units the air handling processes can be best demonstrated by the Mollier $h-x$ chart [14-16]. Some parameters are given such as the temperature and relative humidity of ambient air in the dimensioning phase $\left(t_{O S} ; \varphi_{O S}\right)$, the supply air that enters the room $\left(t_{S} ; \varphi_{S}\right)$ and the outgoing air that leaves the room $\left(t_{O G} ; \varphi_{O G}\right)$.
To perform the energy calculations it is necessary to know the supply air volume flow and the density of the supply air.

The values of indoor air parameters depend on the air distribution of the room and are shown between the supply air and outgoing parameters. The energy analysis is not influenced by the indoor air parameters.

In winter the relative humidity of air coming from the adiabatic humidifier is usually $95 \%$, although this value depends on the intensity of the vaporization. The Mollier h-x chart is available for further data needed to complete the energy analysis. Fig. 4 shows the process of pre-heating (,OS-RH” section), the adiabatic humidifier (,RH-AH" section) and the re-heating (,AH-PH” section) in the dimensioning phase in winter time.

During the change of the ambient air state the pre-heater heats up the air up to the constant enthalpy line that is determined by the adiabatic humidifier, therefore the distribution function of ambient air enthalpy has to be used to define the energy consumption of heating.

On the distribution function (Fig. 5) the above mentioned air state parameters in the dimensioning phase are also shown as well as their changes as the ambient air enthalpy varies during the heating season. The areas of the distribution function that represent the energy consumption of the pre-heater and the reheater can be accordingly drawn. Throughout the calculation of the energy consumption of heating the supply and outgoing air parameters were assumed to be constant during the heating season. This approximation was also applied for the supply and outgoing parameters in the dimensioning phase for the cooling season in the summer.

Fig. 5] shows the areas proportional to the daytime heating energy consumption of the air handling unit (07-19 hours). The symbols are the following:

$F\left(h_{O}\right) \quad:$ the distribution function of ambient enthalpy (07-19 hours, 19-07 hours),

$h_{O S}[\mathrm{~kJ} / \mathrm{kg}]$ : the ambient enthalpy in dimensioning phase in the winter time,

$h_{P H}[\mathrm{~kJ} / \mathrm{kg}]$ : the enthalpy of the air after the pre-heater, which is equal to the enthalpy by the adiabatic humidifier $\left(h_{A H}\right)$,

$h_{R H}[\mathrm{~kJ} / \mathrm{kg}]$ : enthalpy of the air after the re-heater, which is equal to the enthalpy of supply air $\left(h_{S}\right)$.

The physical and mathematical equations were determined 


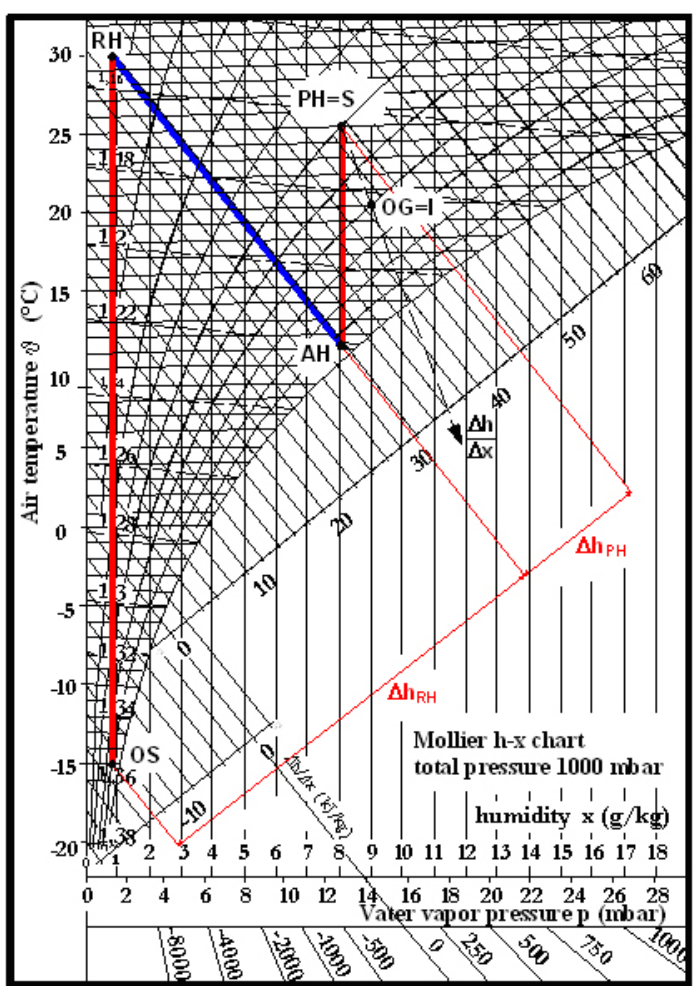

Fig. 4. Air handling processes on the Mollier h-x chart in the dimensioning state in winter time

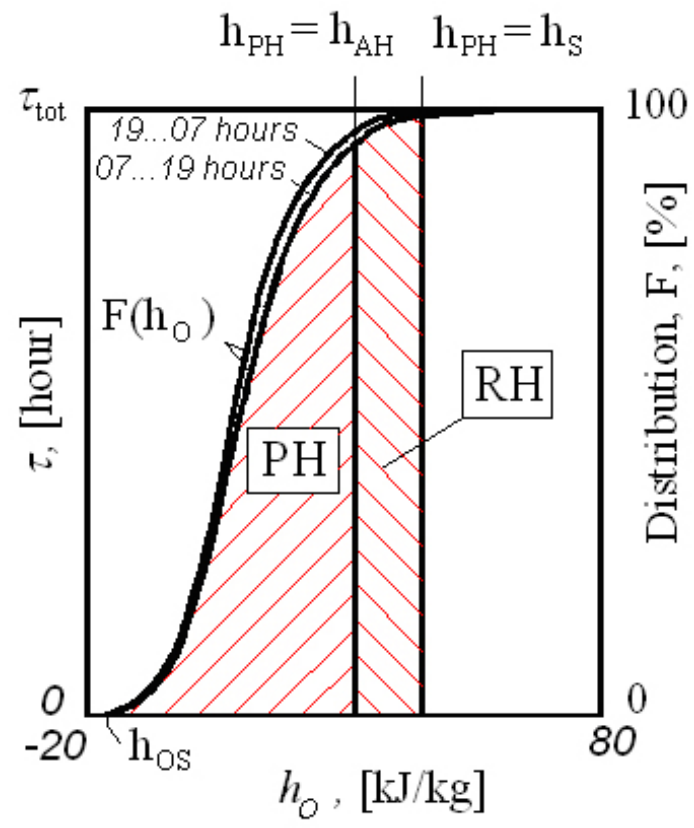

Fig. 5. Areas on the distribution function that represent the energy consumption of the pre-heater and re-heater

accordingly to calculate the energy consumption of the heaters in the fresh air supplied air handling unit.

The energy consumption of the pre-heater:

$$
Q_{P H}=\rho \cdot \dot{V}_{P H} \cdot \int_{h_{O S}}^{h_{P H}} F\left(h_{O}\right) d h[\mathrm{~kJ} / \text { year }]
$$

where: $\rho\left[\mathrm{kg} / \mathrm{m}^{3}\right] \quad$ : air density,

$\dot{V}_{P H}\left[\mathrm{~m}^{3} / \mathrm{h}\right]$ : air volume flow in pre-heater (in the case of fresh air supplied AHU it is equal to the air volume flow in re-heater $\left(\dot{V}_{R H}\right)$ ).

The energy consumption of the re-heater:

$$
Q_{R H}=\rho \cdot \dot{V}_{R H} \cdot \int_{h_{P H}}^{h_{R H}} F\left(h_{O}\right) d h[\mathrm{~kJ} / \text { year }]
$$

where:

$\dot{V}_{U F}\left[\mathrm{~m}^{3} / \mathrm{h}\right]:$ air volume flow in re-heater.

The measurement unit of the integral values is $[\mathrm{kJ} / \mathrm{kg} \cdot \mathrm{h}]$ in the case of the ambient enthalpy distribution function. The result of the calculation therefore is the measurement unit of the energy consumption [kJ].

The calculation procedure for the analysis of the energy consumption of cooling is similar in the summer time. The dimensioning phase for the summer period is specified by the regulations. The average temperature of the surface of cooling coil $\left(t_{S A}\right)$ is about $11-12^{\circ} \mathrm{C}$ when the cooling water temperature is $7 / 12^{\circ} \mathrm{C}$

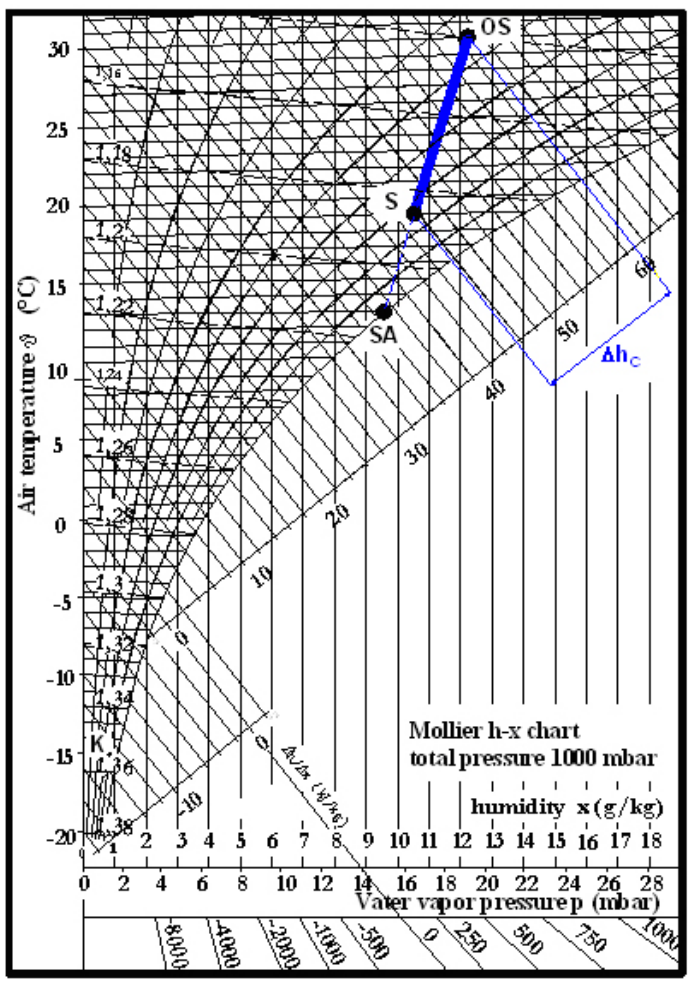

Fig. 6. Cooling process on the Mollier h-x chart in the dimensioning phase in summer time

In light of the above mentioned data the area proportional to the energy consumption of the cooling coil can be drawn in the distribution function. In consideration of the fact that there is condensation on the surface of the cooling coil, the enthalpy distribution function of the ambient air was used to determine the annual energy consumption of the cooling coil (Fig. 77). 


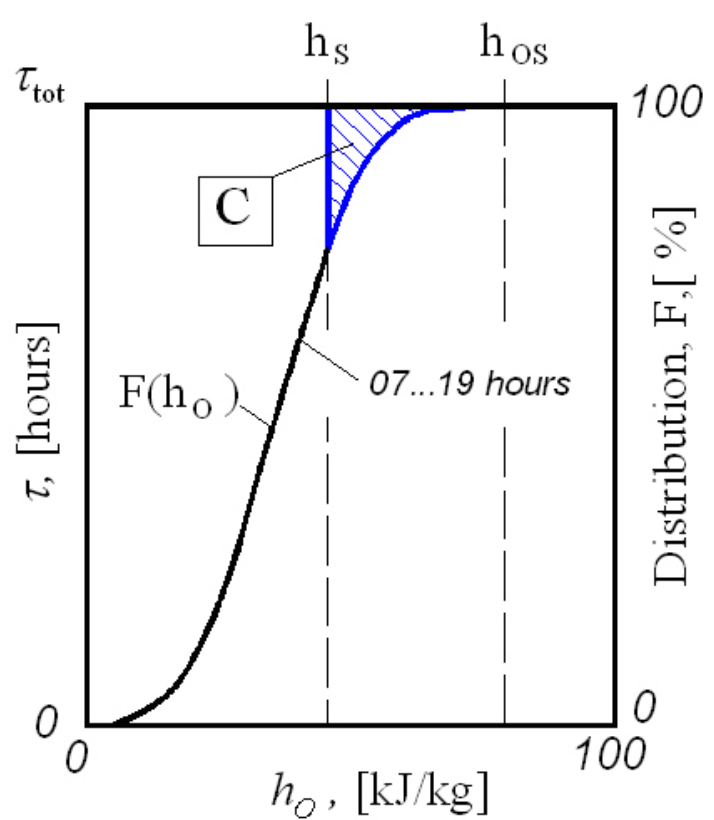

Fig. 7. The area on the distribution function that represents the energy consumption of the cooling coil

The energy consumption of the cooling coil:

$$
Q_{C}=\rho \cdot \dot{V}_{C} \cdot \int_{h_{O S}}^{h_{S}}\left[1-F\left(h_{O}\right)\right] d h[\mathrm{~kJ} / \text { year }]
$$

where:

$\dot{V}_{C}\left[\mathrm{~m}^{3} / \mathrm{h}\right]:$ the air volume flow in the cooling coil,

$h_{S}[\mathrm{~kJ} / \mathrm{kg}]$ : the enthalpy of the supply air.

In light of the energy consumption of the cooling coil the electricity consumption of the compressor can be calculated as follows:

$$
W_{H}=\frac{Q_{H}}{C . O . P .}[\mathrm{kJ} / \text { year }] \text {, or }[\mathrm{kWh} / \text { year }]
$$

where:

C.O.P [-]: the coefficient of the performance of the refrigerating machine [17, 18].

The coefficient of the performance of the refrigerating machine changes during the cooling season. This change was taken into consideration through seasonal average figures.

\section{The results}

In our research work a comparative analysis was made between the new calculation procedure we had developed and the existing international calculation methods. During our analysis the net energy consumption of three air handling units for heating and cooling was determined. The energy analysis was performed using meteorological data for Budapest. The elements of the AHUs are presented in Table 1 . The symbols are the following:
HR : Heat recovery unit,

ER : Energy recovery unit,

PH : Pre-heater,

C : Cooling coil,

AH : Adiabatic humidifier,

SH : Steam humidifier,

RH : Re-heater.

Tab. 1. Elements of the AHUs

\begin{tabular}{llllllll}
\hline & HR & ER & PH & C & AH & SH & RH \\
\hline AHU 1. & X & & X & X & & X & X \\
AHU 2. & & X & X & X & X & & X \\
AHU 3. & & & X & X & & X & X \\
\hline
\end{tabular}

The annual net energy consumption of the analysed air handling units for heating and cooling can be seen in Tables 2,3

Tab. 2. Annual net energy consumption of the AHUs for heating

\begin{tabular}{lllll}
\hline \multicolumn{5}{c}{$\mathbf{Q}_{H}[\mathbf{k W h} /$ year $]$} \\
\hline & Probab. theory & VDI & DIN & EN ISO 13790 \\
\hline $\mathbf{1 .}$ & $\mathbf{1 5 6 6 7}$ & 15080 & 8514 & 26899 \\
$\mathbf{2 .}$ & $\mathbf{2 8 \mathbf { 1 5 8 }}$ & 17150 & 12435 & - \\
$\mathbf{3 .}$ & $\mathbf{3 8 \mathbf { 8 6 5 }}$ & 24927 & 34264 & 42648 \\
\hline
\end{tabular}

Tab. 3. Annual net energy consumption of the AHUs for cooling

\begin{tabular}{lllll}
\hline \multicolumn{5}{c}{$\mathbf{Q}_{H}[\mathrm{kWh} /$ year $]$} \\
\hline & Probab. theory & VDI & DIN & EN ISO 13790 \\
\hline 1. & $\mathbf{1 7 1 7}$ & 1415 & 5726 & 1196 \\
2. & $\mathbf{1 0 0 0}$ & 1415 & 5412 & - \\
3. & $\mathbf{2} \mathbf{4 9 5}$ & 1976 & 5785 & 3062 \\
\hline
\end{tabular}

\section{Conclusions}

The tables show that the results of the energy consumption differ if calculated using the new procedure or VDI 2067 (Blatt 21), DIN V 18599 and MSZ EN ISO 13790:2008 standards. But in each examined case (AHUs 1-3.) the result of the international calculation methods is almost the same as the figures obtained through the new calculation procedure. In the case of AHU 2 equipped with an adiabatic humidifier there is a greater difference with regard to energy consumption for heating. In our view the present international methods do not take into consideration the higher energy consumption of the re-heater, caused by the adiabatic humidifier. Another reason for the different results is that effective regulations define the monthly energy consumption by a single figure only, e.g. average temperature or average enthalpy which only approximately takes into account the changing of the ambient state of the air. 


\section{References}

1 Geoffrey G, David S, Probability and random processes, 2004, pp. 89-90.

2 Elkhuizen P A, Scholten J E, Peitsman H C, Kooijman A, The effect of optimal tuning of the heating/cooling curve in AHU of HVAC system in real practice, ICEBO, Paris, 2004.

3 Max H, Hinweise zur Ausführung und zum Energieverbrauch von Heiz- und Raumlufttechnischen Anlagen, VDI-Verl., Düsseldorf, 1992.

4 Henze G P, Felsmann C, Kalza D E, Herkel S, Primary energy and comfort performance of ventilation assisted thermo-active building systems in continental climates, Energy and Buildings (2008), 104.

5 László K, Miklós K, Analysis of air treatment equipment using the probability theory, $14^{\text {th }}$ Building Services, Mechanical and Building Industry Days, Debrecen, 2008.

6 Jansen W, Statistische Untersuchung über Abhängigkeiten von Temperatur, Feuchte und Energieverbrauch in Wohnungen mit verschiedenen Lüftungsystemen, Dortmund, 1989.

7 Joseph C. Lam, Sam C.M. Hui, Apple L.S. Chan, A statistical approach of the development of a typical meteorological year for Hong Kong, Architectural Science Review 39, 201-209.

8 Zhou Jin, Wu Yezheng, Yan Gang, A stochastic method to generate bin weather data in Nanjing, China, Energy Conversion and Management, 18431850.

9 Kajtár L, Klímatechnikai rendszerek energetikai, gazdasági elemzése valószínúségelméleti alapon. CD kiadvány.

10 Pfafferott J, Herkel S, Wambsganß M, Design, monitoring and evaluation of a low energy office building with passive cooling by night ventilation, Energy and Buildings (2004), 458.

11 Recknagel, Sprenger, Schramek, Fütés- és klímatechnika 2000/II. kötet, Dialóg Campus Kiadó, Budapest-Pécs, 2000.

12 Asiedo Y, Besant R W, Simonson C J, Cost-Effective Design of Dual Heat and Energy Recovery Exchangers for $100 \%$ Ventilation Air in HVAC Cabinet Units, ASHRAE Transactions 111 (2005), 858-863. Part 1.

13 Kiss R, Légtechnikai adatok, Múszaki Könyvkiadó, Budapest, 1980.

14 Jones W P, Air Conditioning Engineering, 2001.

15 Eickenhorst H, Einführung in die Klimatechnik, Erläuterungen zum $h-x$ Diagramm, 1998.

16 László K, Miklós K, Evaluation of energy demand of air-conditioning systems based on probability theory, The 6th IASME/WSEAS International Conference on Heat Transfer, Thermal Engineering and Environment, Rhodos, 2008, pp. 266-270.

17 Jakab Zoltán, Kompresszoros hütés I., Magyar Mediprint Szakkiadó Kft.

18 Ahmadul Ameen, Refrigeration and air conditioning, 2006. 